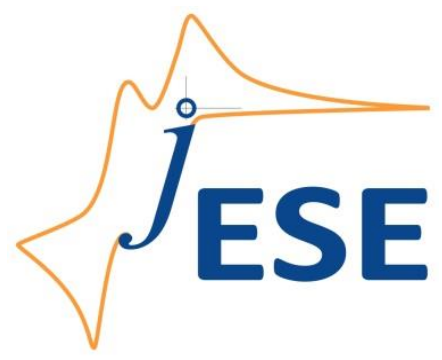

Open Access : : ISSN 1847-9286

www.jESE-online.org

Original scientific paper

\title{
Thermodynamic, adsorption and corrosion inhibitive behaviour of benzyl nicotinate on cold rolled steel in sulphuric acid solution
}

\author{
Mutugadahalli Rangaswamy Vinutha, Thimmappa Venkatarangaiah Venkatesha \\ Department of Chemistry, School of Chemical Science, Jnana Sahyadri Campus, Kuvempu \\ University, Shankaraghatta-577451, Karanataka, India \\ ${ }^{\square}$ Corresponding Author: drtvvenkatesha@yahoo.co.uk
}

Received: September 24, 2015; Revised: November 27, 2015; Accepted: November 28, 2015

\begin{abstract}
The inhibition performance of benzyl nicotinate (BN) on corrosion of cold rolled steel (CRS) in $0.5 \mathrm{M} \mathrm{H}_{2} \mathrm{SO}_{4}$ solution has been investigated using weight loss, Tafel polarization and electrochemical impedance spectroscopy (EIS). The BN acts as mixed type inhibitor. The thermodynamic parameters indicate the comprehensive nature adsorption of $B N$ on CRS which obey Langmuir isotherm. Morphological investigation of corrosion inhibition is carried out using AFM and optical microscopic studies support the formation of inhibitor film on CRS. There is a good agreement between the values of weight loss measurements and electrochemical studies.
\end{abstract}

\section{Keywords}

EIS, Inhibitor, Thermodynamic properties, Langmuir isotherm, AFM, Optical microscopy

\section{Introduction}

The study on the rusting of steel received great deal of attention by academicians due to its application in different fields. The methods of various natures have been reported in scientific journals to control the rust [1]. The use of inhibitor is considered as the best and most commonly used practical method to control the corrosion of steel. In recent years different type organic compounds are used as inhibitors in liquid medium for steel corrosion and their role during the process of corrosion has been extensively studied. These inhibitors enter in to the metal-solution interface and replace water molecules [2-3]. The hetero atoms like oxygen, nitrogen, sulphur, and phosphorus, triple bonds, and aromatic rings of compounds enhances their population at the metal- solution interface making a sort of barrier between metal and solution. The inhibitor 
efficiency of heterocyclic organic compounds follows the sequence: oxygen $<$ nitrogen $<$ sulphur $<$ phosphorus. The electronic characteristic of the inhibitor molecules, aromaticity, steric factor, molecular mass, presence of functional groups like $-\mathrm{C}=\mathrm{O},-\mathrm{N}=\mathrm{N}-,-\mathrm{OH},-\mathrm{COOR}$, the chemical composition of the solution, the nature of the metal surface, the temperature and the potential at the metal-solution interface determine efficacy of the inhibitor. The primary requirement for adsorption of inhibitor depends on the existence of attractive forces between the inhibitor and the metal. The adsorption may be physisorption, chemisorption or a combination of both [4-9].

In the present study, the selected inhibitor was benzyl nicotinate (BN), which is pyridine heterocycle containing nitrogen and -COOR group, where the R-group is a benzyl group. All these structural features of $\mathrm{BN}$ are enough to produce required attractive force responsible for its adsorption to metal surface. In the present study, inhibitive effect of $\mathrm{BN}$ on the corrosion of cold rolled steel (CRS) in $0.5 \mathrm{M} \mathrm{H}_{2} \mathrm{SO}_{4}$ solution was verified using weight loss, EIS and Tafel polarization method. The morphology of the CRS surface was determined using atomic force microscopy (AFM) and optical microscopy.

\section{Experiment}

Sample

The experiments were performed on CRS with the compositions of $0.14 \% \mathrm{C}, 0.4 \% \mathrm{Mn}, 0.025 \%$ $\mathrm{P}$, and $0.0008 \% \mathrm{~S}, 0.025 \% \mathrm{Si}, 0.003 \% \mathrm{Al}$ and rest of Fe.

\section{Solution}

The test solution of $0.5 \mathrm{M} \mathrm{H}_{2} \mathrm{SO}_{4}$ was prepared using double distilled Millipore water. The

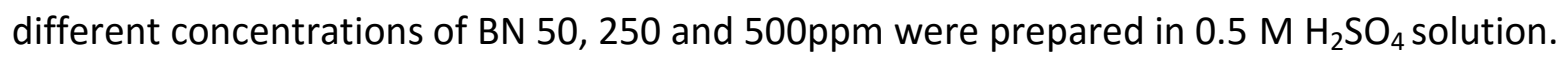

\section{Weight loss measurement}

The CRS specimens of dimension $4 \times 2 \times 0.5 \mathrm{~cm}$ were used for weight loss measurements and were abraded with a series of emery paper from 220, 330, 400, 600 and 1200 grades. The specimens were washed with Millipore water, rinsed in acetone and dried in air. The weight loss incurred by CRS specimens in corrosion experiments were determined by weighing the samples before and after immersing in $100 \mathrm{~cm}^{3}$ of $0.5 \mathrm{M} \mathrm{H}_{2} \mathrm{SO}_{4}$. The corrosion experiments were also conducted at temperature $303,313,323$, and $333 \mathrm{~K}$. The experiments were performed in static open aerated condition.

The corrosion rate $\left(v_{\text {corr }}\right)$ of CRS was determined using the following relation:

$$
\nu_{\text {corr }}=\frac{\Delta m}{S t}
$$

where $v_{\text {corr }}$ is the corrosion rate of mild steel $\left(\mathrm{g} \mathrm{cm}^{-2} \mathrm{~h}^{-1}\right), \Delta m$ is the corrosion weight loss of mild steel $(\mathrm{g}), S$ is the surface area of mild steel specimen $\left(\mathrm{cm}^{2}\right)$, and $t$ is the time of exposure. The percentage inhibition efficiency was calculated using the following relationship

$$
I E / \%=\frac{v_{\text {corr }}^{o}-v_{\text {corr }}}{v_{\text {corr }}^{o}} \times 100
$$

where $v_{\text {corr }}^{0}$ and $v_{\text {corr }}$ are the corrosion rates of CRS in the absence and presence of BN respectively. 


\section{Electrochemical measurements}

The electrochemical measurements were conducted in a conventional three electrode glass cell using CHI660D electrochemical analyser (USA made). The CRS specimen of $1 \mathrm{~cm}^{2}$ exposed area with $5 \mathrm{~cm}$ long stem isolated with araldite resin was used as working electrode and platinum wire, Calomel electrode were used as counter and reference electrode respectively. Prior to polarization and electrochemical impedance spectroscopic measurements (EIS), a stabilization period of $30 \mathrm{~min}$ was allowed to establish a steady state open circuit potential (OCP). Each experiment was carried out in triplicate and the average values were reported.

EIS measurements were done at OCP in the frequency range from $0.1 \mathrm{~Hz}$ to $10 \mathrm{kHz}$ with the amplitude of $5 \mathrm{mV}$. The inhibition efficiency of EIS measurement were calculated using the following equation

$$
I E_{(\mathrm{imp})} / \%=\frac{R_{\mathrm{ct}}-R_{\mathrm{ct}}^{\circ}}{R_{\mathrm{ct}}} \times 100
$$

where $R_{\mathrm{ct}}$ and $R_{\text {ct }}^{0}$ are charge transfer resistance of working electrode with and without inhibitor, respectively.

Polarization plots were obtained in potential range from $-200 \mathrm{mV}$ to $-1000 \mathrm{mV}$ with the scan rate of $10 \mathrm{mV} / \mathrm{s}$ at OCP. The corrosion parameters like corrosion current density $\left(I_{\text {corr }}\right)$, corrosion potential $\left(E_{\text {corr }}\right)$, catodic $\left(\beta_{\mathrm{c}}\right)$ and anodic $\left(\beta_{\mathrm{a}}\right)$ Tafel slopes were calculated. Inhibition efficiency is calculated using the relation as follows,

$$
I E_{(\mathrm{pol})} / \%=\frac{I_{\text {corr }}^{\circ}-I_{\text {corr }}}{I_{\text {corr }}^{\circ}} \times 100
$$

where $I^{0}$ corr and $I_{\text {corr }}$ are the corrosion current density in the absence and in presence of inhibitor respectively.

\section{Morphological studies}

The surface morphology of CRS samples were investigated using both Atomic force microscopy (AFM - Bruker model) and optical microscopy using Olympus CX31 microscope.

\section{Results and discussions}

\section{Polarisation studies}

Figure 1 shows the typical polarisation curve for CRS generated at room temperature without and with different concentration of inhibitor BN. The corresponding electrochemical parameters such as corrosion potential $\left(E_{\text {corr }}\right)$, corrosion current density $\left(I_{\text {corr }}\right)$, cathodic $\left(\beta_{\mathrm{c}}\right)$ and anodic $\left(\beta_{\mathrm{a}}\right)$ Tafel slopes and inhibition efficiency are given in Table 1 . From the Table 1 it is indicated that there is decrease in the corrosion current density $\left(I_{\text {corr }}\right)$ value with increase of concentration of inhibitor, which suggested the adsorption of inhibitor molecule on surface of steel and thus acting as a barrier for charge and mass transfer reactions [10]. Furthermore, with increase in concentration of inhibitor $\mathrm{BN}$ there is no significant shift in the values of either cathodic ( $\beta_{\mathrm{c}}$ ) or anodic $\left(\beta_{\mathrm{a}}\right)$ slope which infers the adsorption BN on CRS controls both anodic metal dissolution and cathodic hydrogen evolution processes. Moreover, the value of $\Delta E_{\text {corr }}$ is within 5-30 $\mathrm{mV}$ [11], hence $\mathrm{BN}$ act as mixed inhibitor for $\mathrm{CRS}$ in $0.5 \mathrm{M} \mathrm{H}_{2} \mathrm{SO}_{4}$. 
Table 1. Electrochemical polarization parameters of CRS at $0.5 \mathrm{M} \mathrm{H}_{2} \mathrm{SO}_{4}$ solution in absence and presence of $B N$ measured at $303 \mathrm{~K}$

\begin{tabular}{lccccc}
\hline Concentration, $\mathrm{ppm}$ & $-E_{\text {corr }} / \mathbf{~ m V}$ & $\beta_{\mathrm{c}} / \mathrm{mV} \mathrm{dec}^{-1}$ & $\beta_{\mathrm{a}} / \mathrm{mV} \mathrm{dec}^{-1}$ & $\boldsymbol{I}_{\text {corr }} / \mathrm{mA} \mathrm{cm}^{-2}$ & IE / \% \\
\hline 0 & 519 & 188.0 & 154.0 & 3.991 & \\
50 & 516 & 170.9 & 129.2 & 1.347 & 66 \\
250 & 509 & 158.4 & 107.9 & 0.715 & 82 \\
500 & 504 & 148.9 & 92.0 & 0.333 & 92 \\
\hline
\end{tabular}

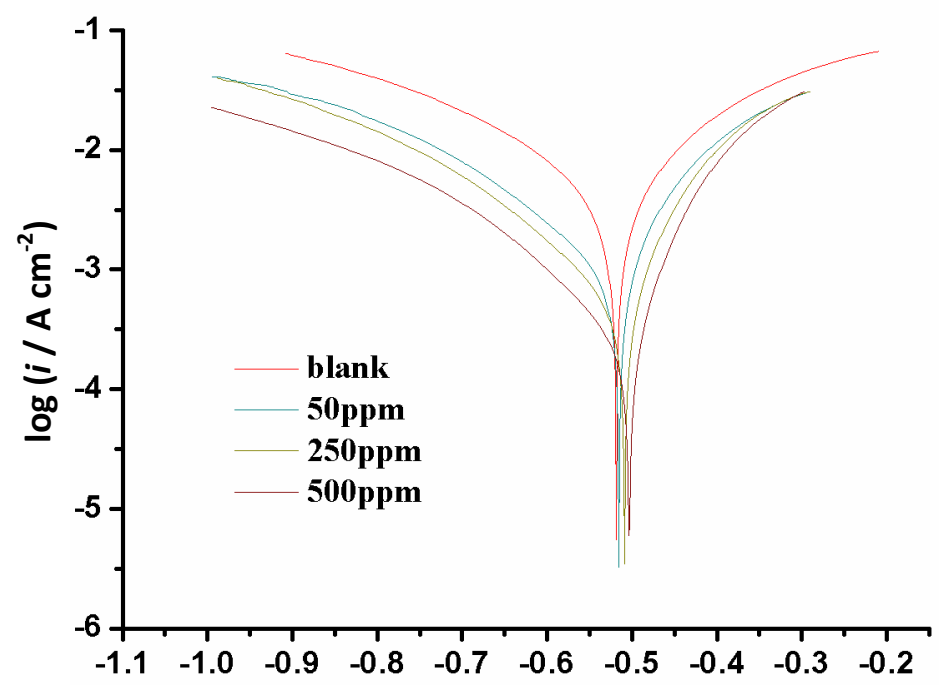

E / V vs. SCE

Figure 1. Tafel polarization response of various concentration of $\mathrm{BN}$ in $0.5 \mathrm{M} \mathrm{H}_{2} \mathrm{SO}_{4}$ solution

\section{Electrochemical impedance studies}

The EIS findings of CRS in $0.5 \mathrm{M} \mathrm{H}_{2} \mathrm{SO}_{4}$ both in absence and in presence of different concentration of BN were (analysed using Zsim win 3.21) presented in Table 2. Corrosion behaviour at the studied frequency ranges is represented in Nyquist and Bode plots as in Figures 2, 3 and 4. The Nyquist plots exhibit single slightly depressed semicircles and one time constant in Bode plots, which suggests that metal dissolution is controlled by charge transfer process [12].

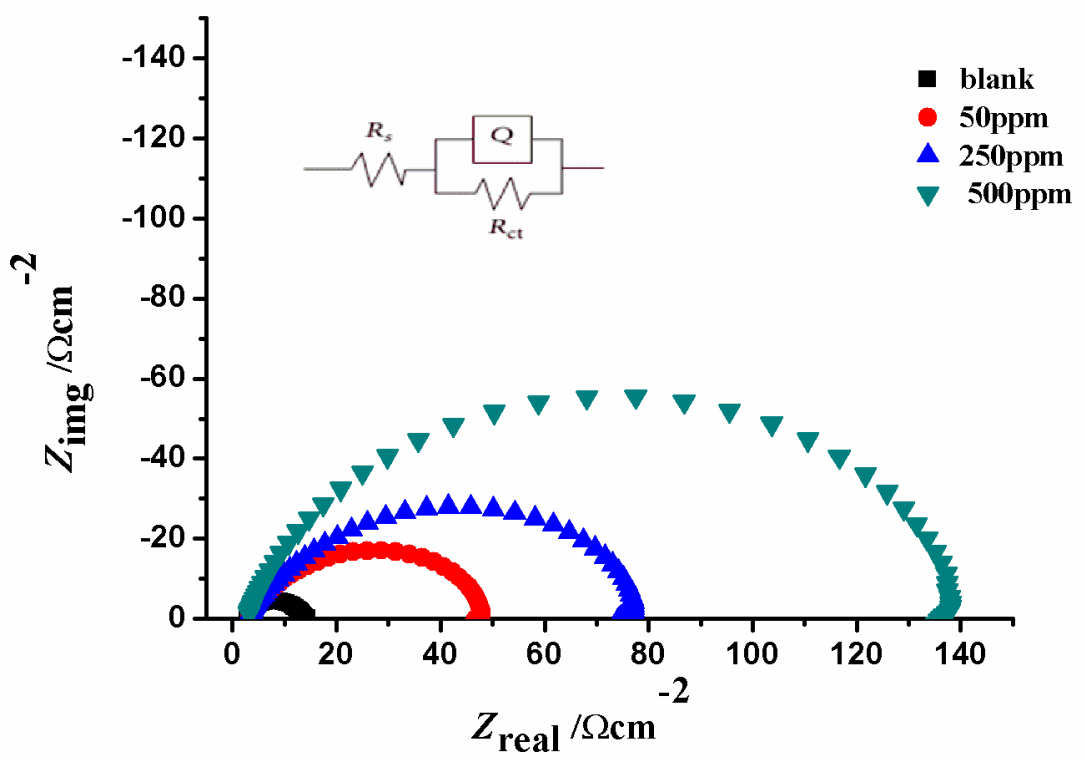

Figure 2. Nyquist plots for different concentration of $\mathrm{BN}$ in $0.5 \mathrm{M} \mathrm{H}_{2} \mathrm{SO}_{4}$ solution. 
The depression in Nyquist semicircle is ascribed to some physical nature of surface i.e., inhomogeneity, roughness and active site of surface. The EIS values were examined using a suitable equivalent circuit model shown in the Figure 2 , where $R_{\mathrm{s}}$ is the solution resistance and $R_{\mathrm{ct}}$ is the charge transfer resistance, $Q$ is the constant phase element, which is used in place of pure capacitor, in order to explain the deviation of electrodes from ideal dielectric behaviour, which is related to surface inhomogeneity [13]. The impedance of constant phase element $\left(Z_{\mathrm{CPE}}\right)$ is given by the following equation:

$$
Z_{\mathrm{CPE}}=Y_{0}^{-1}(i \omega)^{-n}
$$

where $Y_{0}$ is CPE constant, $i^{2}=-1$, an imaginary number, $\omega$ is angular frequency and $\mathrm{n}$ is CPE exponent which used to assess the surface inhomogeneity, resulting from surface roughness, inhibitor adsorption, porous layer formation, etc. [14]. The capacitance $\left(C_{\mathrm{dl}}\right)$ of constant phase element is calculated using the following relation

$$
C_{\mathrm{dl}}=\left(Q R_{\mathrm{ct}}{ }^{1-\mathrm{n}}\right)^{1 / \mathrm{n}}
$$

From the Nyquist plot, it is observed that with an increase in inhibitor concentration, there is an increase in semicircle diameter which corresponds to $R_{\mathrm{ct}}$ values. It accounts from the table that, there is decrease in the $R_{\mathrm{ct}}$ values and increase in $C_{\mathrm{dl}}$ values with increase in concentration of inhibitor. This resulted from replacement of water molecule from the steel surface by the inhibitor molecule thereby reducing the active sites of corrosion. The same result is depicted in Bode diagram, i.e., increment in phase angle with increase of inhibitor concentration is corresponding to decrease in surface inhomogeneity with inhibitor adsorption onto steel surface [15]. The above discussion it is concluded that $\mathrm{BN}$ works as efficient inhibitor for CRS in $0.5 \mathrm{M} \mathrm{H}_{2} \mathrm{SO}_{4}$.

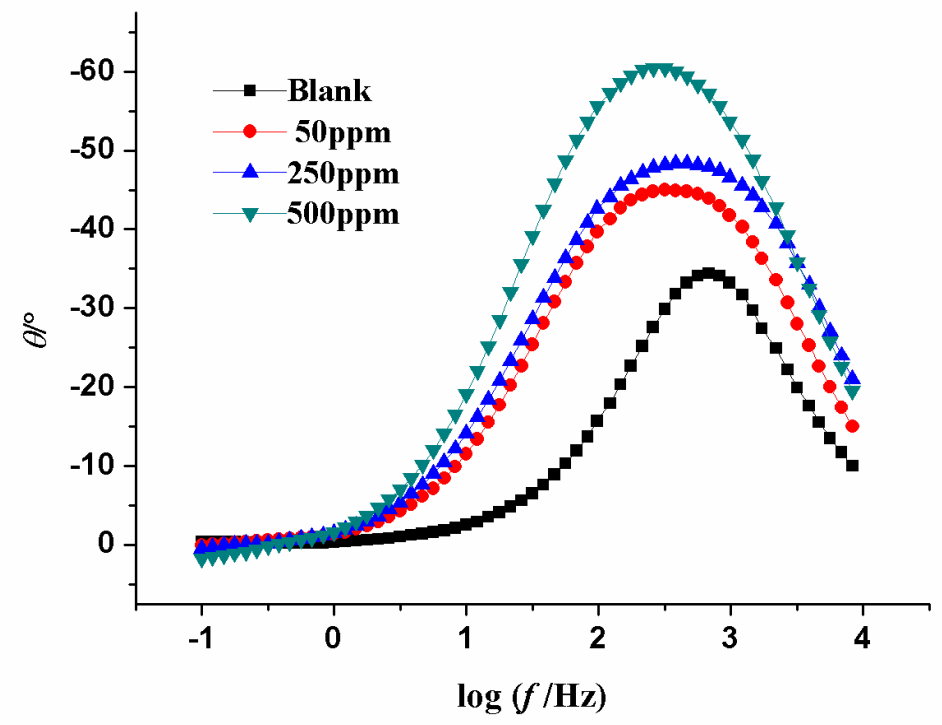

Figure 3. Bode phase angle plots for different concentration of $\mathrm{BN}$ in $0.5 \mathrm{M} \mathrm{H}_{2} \mathrm{SO}_{4}$ solution

Table 2. Electrochemical impedance parameters of CRS at $0.5 \mathrm{M} \mathrm{H}_{2} \mathrm{SO}_{4}$ solution in absence and

\begin{tabular}{|c|c|c|c|c|c|}
\hline Concentration, ppm & $R_{\mathrm{ct}} / \Omega \mathrm{cm}^{-2}$ & $Q / \mathrm{S}^{\mathrm{n}} \Omega^{-1} \mathrm{~cm}^{-2}$ & $\mathbf{n}$ & $C_{\mathrm{dl}} / \mu \mathrm{F} \mathrm{cm}$ & IE / \% \\
\hline 0 & 11.26 & $1.588 \times 10^{-4}$ & 0.86 & 57.2 & \\
\hline 50 & 46.2 & $2.296 \times 10^{-4}$ & 0.76 & 52.6 & 76 \\
\hline 250 & 76.16 & $1.655 \times 10^{-4}$ & 0.76 & 41.8 & 85 \\
\hline 500 & 136.8 & $0.853 \times 10^{-4}$ & 0.85 & 38.9 & 92 \\
\hline
\end{tabular}
presence of $B N$ measured at $303 \mathrm{~K}$. 


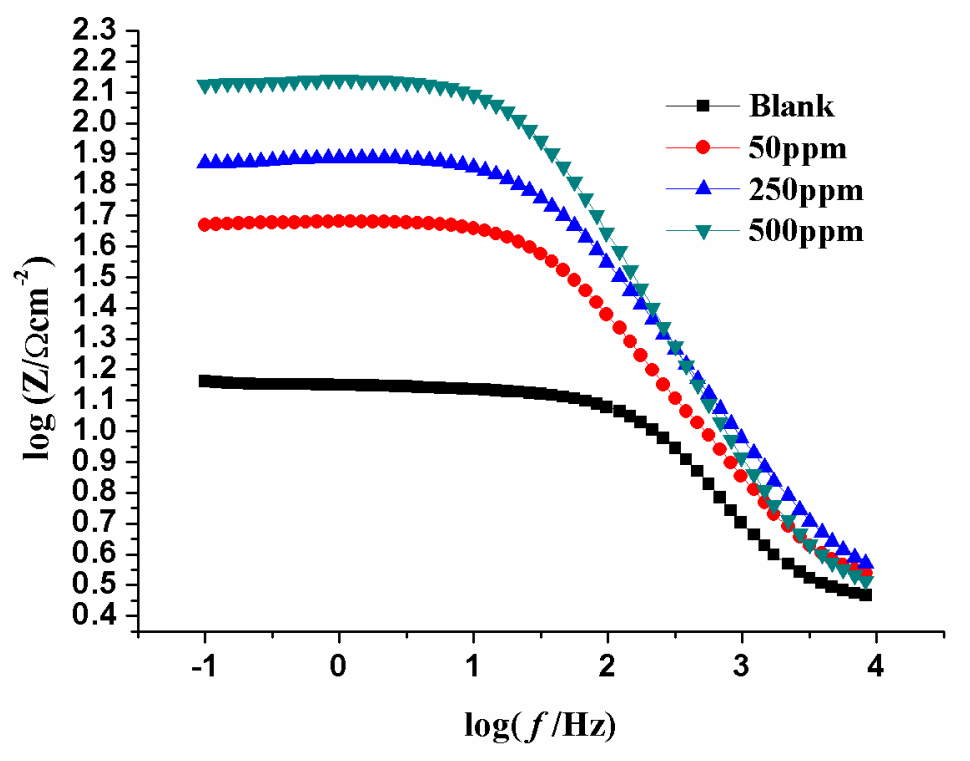

Figure 4. Bode phase plots for different concentration of $\mathrm{BN}$ in $0.5 \mathrm{M} \mathrm{H}_{2} \mathrm{SO}_{4}$ solution.

\section{Weight loss experiment}

The effect of inhibitor concentration on corrosion rate at different temperature ranging between 303-333 $\mathrm{K}$ is as shown in the Figure 5 and the corresponding values are tabulated in Table 3. The corrosion rate decreases with increasing concentration of inhibitor due to the increase of surface coverage of inhibitor [16]. It is clear from the Figure 5 that the corrosion rate decreases with the increase in the concentration of $\mathrm{BN}$. The corrosion rate increases more rapidly in the absence and in the presence of $50 \mathrm{ppm}$ of BN concentration, however, a small decrease in the corrosion rate values at $250 \mathrm{ppm}$ and to very lesser extent in $500 \mathrm{ppm}$ with the rise of temperature. The increase in corrosion rate and hence decreasing value of inhibition efficiency with rise of temperature is indicative of physisorption of BN molecule on CRS.

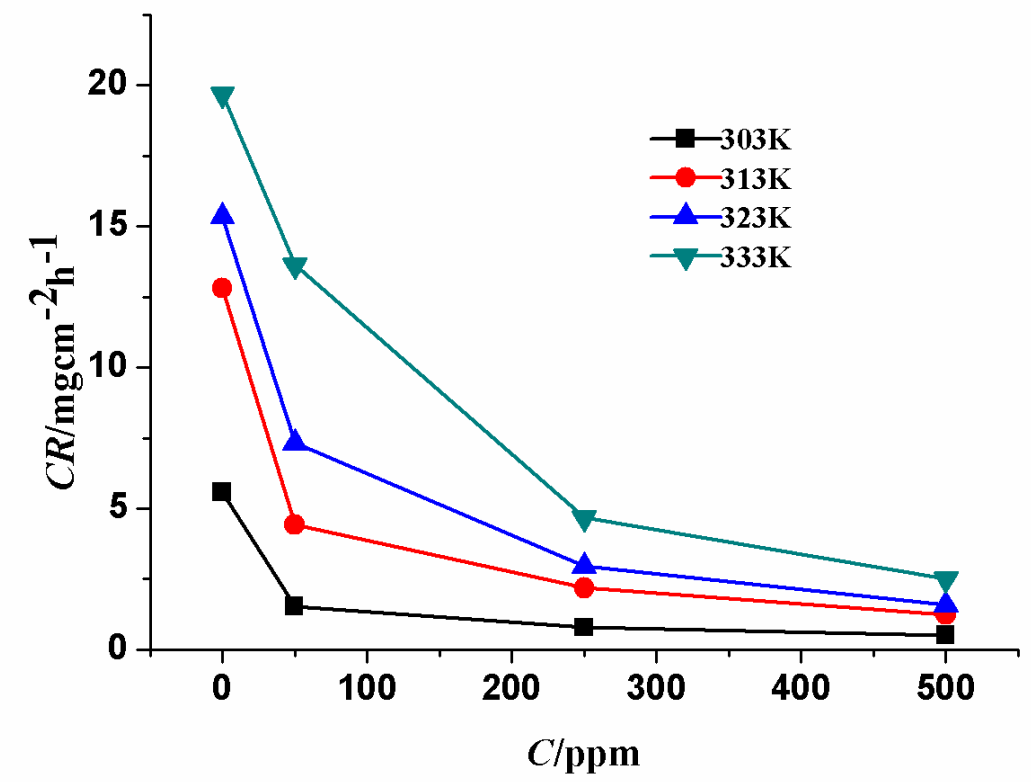

Figure 5. Variation of corrosion rate with concentration at different temperature 
Adsorption isotherm and thermodynamic parameters studies

Corrosion inhibitor, BN, adsorbs on steel surface preventing its surface contact with the corrosive media and thus preventing steel dissolution. In order to gain deeper understanding about the mode of adsorption, the experimentally calculated data were verified with the different adsorption isotherm equations. The best fit was obtained with Langmuir isotherm equation represented below:

$$
\frac{C}{\theta}=\frac{1}{K_{\text {ads }}}+C
$$

where $C$ is concentration of inhibitor, $\theta$ is surface coverage and $K_{\text {ads }}$ adsorption equilibrium constant. Using the values of $K_{\text {ads }}$, we were able to calculate the thermodynamic parameters like $\Delta G_{\text {ads }}, \Delta H$ and $\Delta S$ and which are depicted in the Table 4 . The Langmuir isotherm equation is based on the assumption that the adsorption of organic molecules on metallic surface is monolayer without any chemical interaction between them. Furthermore, the adsorption of the molecule on to metal surface depends upon the chemical structure and charge distribution of molecule and also depends on surface charge of metal [17]. We can classify the adsorption as physisorption if $\Delta G_{\text {ads }}<$ $20 \mathrm{~kJ}$, chemisorptions if $\Delta G_{\text {ads }}>40 \mathrm{~kJ}$ or comprehensive adsorption if $\Delta G_{\text {ads }}$ in between $20-40 \mathrm{~kJ}$.

Table 3. Corrosion rate and the inhibition efficiencies at various temperatures at different concentration of $\mathrm{BN}$ in $0.5 \mathrm{M} \mathrm{H}_{2} \mathrm{SO}_{4}$ solution as obtained from weight loss experiment.

\begin{tabular}{|c|c|c|c|c|c|c|c|c|}
\hline \multirow{3}{*}{ Concentration, ppm } & \multicolumn{8}{|c|}{ Temperature, $\mathrm{K}$} \\
\hline & \multicolumn{2}{|l|}{303} & \multicolumn{2}{|l|}{313} & \multicolumn{2}{|l|}{323} & \multicolumn{2}{|c|}{333} \\
\hline & $\begin{array}{c}v_{\text {corr }} / \\
\mathrm{mg} \mathrm{cm}^{-2} \mathrm{~h}^{-1}\end{array}$ & IE / \% & $\begin{array}{c}v_{\text {corr }} / \\
\mathrm{m} \mathrm{cm}^{-2} \mathrm{~h}^{-1}\end{array}$ & IE / \% & $\begin{array}{c}v_{\text {corr }} / \\
\mathrm{mg} \mathrm{cm}^{-2} \mathrm{~h}^{-1}\end{array}$ & IE / \% & $\begin{array}{c}v_{\text {corr }} / \\
\mathrm{mg} \mathrm{cm}^{-2} \mathrm{~h}^{-1}\end{array}$ & $\begin{array}{c}\text { IE / } \\
\% \\
\end{array}$ \\
\hline 0 & 5.5625 & & 12.8 & & 15.34 & & 19.68 & \\
\hline 50 & 1.525 & 72.58 & 4.425 & 65.29 & 7.31 & 52.32 & 13.63 & 31 \\
\hline 250 & 0.775 & 86.07 & 2.175 & 82.94 & 2.95 & 80.76 & 4.663 & 76 \\
\hline 500 & 0.5 & 91.01 & 1.225 & 90.39 & 1.575 & 89.73 & 2.500 & 88 \\
\hline
\end{tabular}

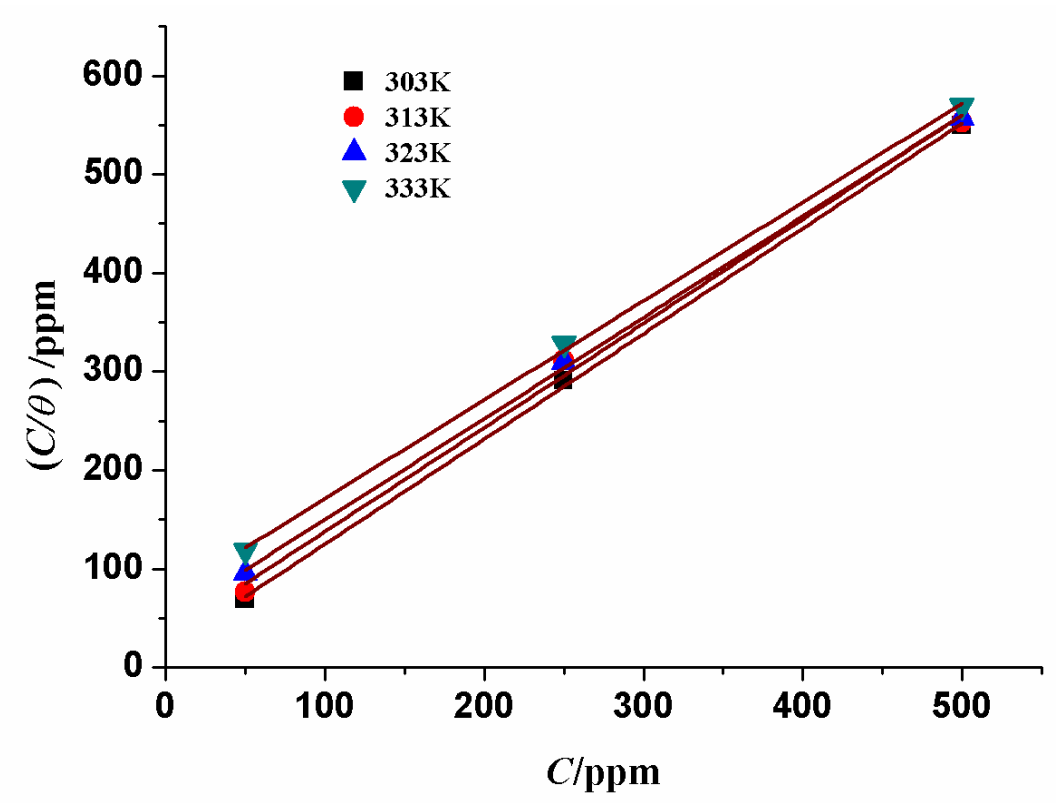

Figure 6. Langmuir adsorption of $\mathrm{BN}$ on the surface of $C R S$ in $0.5 \mathrm{M} \mathrm{H}_{2} \mathrm{SO}_{4}$ at various temperatures. 
Table 4. Thermodynamic parameters for CRS in $0.5 \mathrm{M} \mathrm{H}_{2} \mathrm{SO}_{4}$ solution obtained from weight loss method.

\begin{tabular}{cccccc}
\hline Temperature, $\mathrm{K}$ & $\boldsymbol{R}^{\mathbf{2}}$ & $\boldsymbol{K}_{\mathrm{ads}} / \mathbf{M}^{-\mathbf{1}}$ & $-\boldsymbol{\Delta} \boldsymbol{G} / \mathrm{kJ} \mathrm{mol}^{-1}$ & $-\Delta \boldsymbol{H} / \mathrm{kJ} \mathrm{mol}^{-1}$ & $\Delta \boldsymbol{S} / \mathrm{J} \mathrm{mol}^{-1} \mathbf{K}^{-}$ \\
\hline 303 & 0.999 & 53987 & 37.567 & & \\
313 & 0.994 & 30951 & 37.360 & & \\
323 & 0.999 & 21011 & 37.513 & 37.262 & 34.141 \\
333 & 0.999 & 14022 & 37.555 & & \\
\hline
\end{tabular}

The $\Delta G_{\text {ads }}$ values around $-37 \mathrm{~kJ}$ implied that the adsorption of $\mathrm{BN}$ molecule on to CRS is comprehensive in nature i.e., the nature is in between to that of physisorption and chemisorptions [18]. Thus, $\Delta G_{\text {ads }}$ can be calculated according to the following equation:

$$
K_{\text {ads }}=\frac{1}{55.5} \exp \left(\frac{-\Delta G_{\text {ads }}}{R T}\right)
$$

The value of $\Delta H$ and $\Delta S$ can be calculated using van't-Hoff equation expressed as follows:

$$
\ln K_{\text {ads }}=\frac{1}{55.5}+\frac{-\Delta H_{\text {ads }}}{R T}+\frac{\Delta S_{\text {ads }}}{R}
$$

The graph of $\ln \left(K_{\text {ads }}\right)$ againt $1 / T$ gives a straight line with a slope of $(-\Delta H / R)$ and intercept equal to $[\Delta S / R+\ln (1 / 55.5)]$ and are represented in Table 4. Further, the negative values of $\Delta G_{\text {ads }}$ suggest spontaneous adsorption of inhibitor molecule on steel surface. The negative value of $\Delta H$ indicates adsorption is exothermic in nature and hence there is decrease in inhibition efficiency with increase in temperature.

Generally, exothermic process is attributed to either physisorption or chemisorption while endothermic process is for pure chemisorption. Furthermore, if the value of $\Delta H<41.86 \mathrm{~kJ} / \mathrm{mol}$ then it is physisorption, while for chemisorption $\Delta H$ values in and around $100 \mathrm{~kJ} / \mathrm{mol}$ [21-23]. For the present case, $\Delta H_{\text {ads }}=-37.26 \mathrm{~kJ}$ is pure physisorption of inhibitor BN. The positive value of $\Delta S$ infers that adsorption of inhibitor onto metal surface is accompanied by increase in entropy. This thermodynamic value entropy is algebraic sum of decrease in entropy of solute and increase in entropy of solvent and hence the positive value of entropy corresponds to increase in solvent entropy [24].

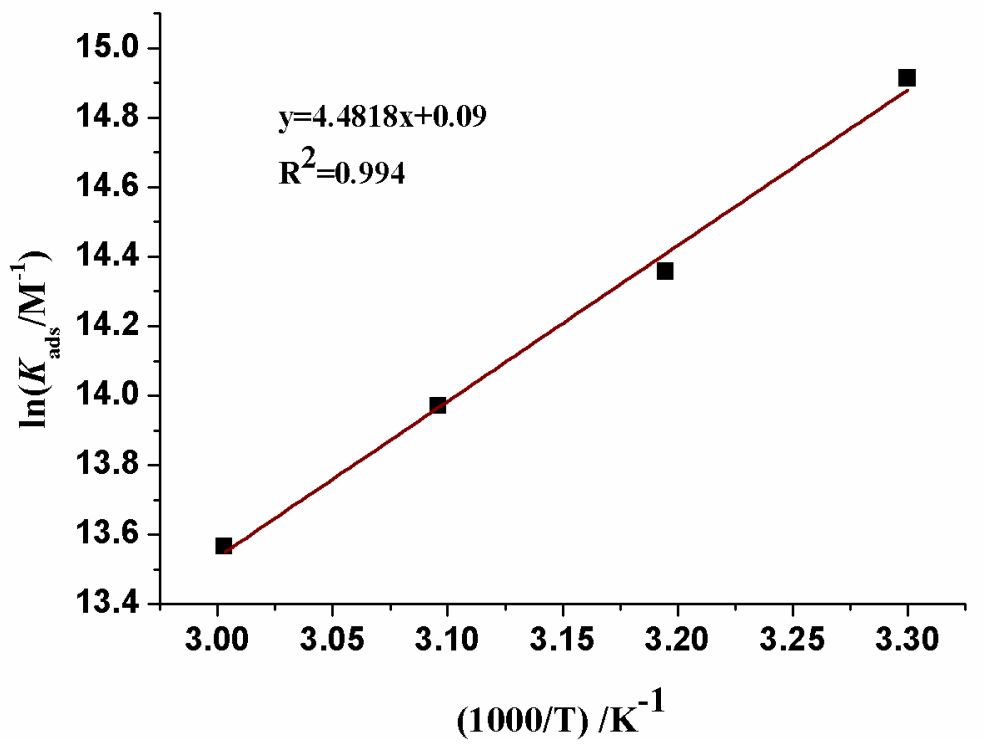

Figure 7. Relation between In $\mathrm{K}_{\text {ads }}$ against $1 / \uparrow$ 


\section{AFM surface characterization studies}

In recent developments, AFM emerged as powerful technique for characterising microstructures of materials. AFM provides powerful means to study the surface morphology in the micro or nano ranges and for evaluating the influence of inhibitor on the corrosion process [19]. Figure 9 shows three dimensional AFM images of polished cold rolled steel (reference sample) (a), of CRS specimens immersed in $0.5 \mathrm{M} \mathrm{H}_{2} \mathrm{SO}_{4}$ solution (b) and of CRS specimens immersed in $0.5 \mathrm{M} \mathrm{H}_{2} \mathrm{SO}_{4}+500$ ppm of $\mathrm{BN}$ (c), respectively. It is apparent from the Figure 8 that the inhibited surface is more uniform when compared to the surface immersed in $0.5 \mathrm{M} \mathrm{H}_{2} \mathrm{SO}_{4}$ solution.
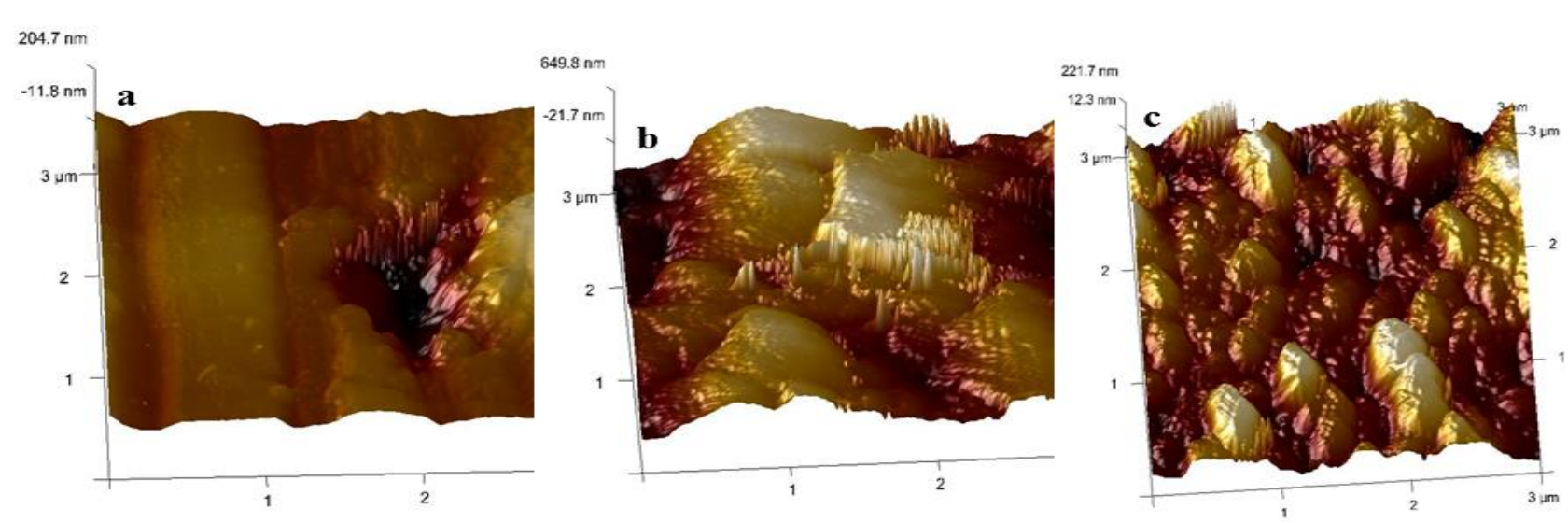

Figure 8. 3D AFM images of polished cold rolled steel (a), CRS specimens immersed in $0.5 \mathrm{M} \mathrm{H}_{2} \mathrm{SO}_{4}(\boldsymbol{b})$ and in $0.5 \mathrm{M} \mathrm{H}_{2} \mathrm{SO}_{4}+500$ ppm of $\mathrm{BN}$ (c).

The AFM analysis directly measures the surface roughness with the roughness parameters, peak height and texture and surface area of entire surface. Average roughness $\left(R_{\mathrm{a}}\right)$ is the arithmetic average of the absolute values of the surface height deviations measured from the mean plane. The root mean square roughness $\left(R_{\mathrm{q}}\right)$ is the root mean square average of height deviations taken from the mean data plane and the $\left(R_{\max }\right)$ specifies the maximum vertical distance between the highest and lowest data points in the image i.e., it gives the maximum peak to valley height values [20]. The values so obtained are represented in a Table 5

Table 5. Roughness parameters for CRS as obtained from AFM studies

\begin{tabular}{lccc}
\hline Samples status & $\begin{array}{c}\text { Average roughness } \\
\boldsymbol{R}_{\mathrm{a}} / \mathbf{n m}\end{array}$ & $\begin{array}{c}\text { RMS roughness } \\
\boldsymbol{R}_{\mathbf{q}} / \mathbf{n m}\end{array}$ & $\begin{array}{c}\text { Peak to valley height } \\
\boldsymbol{R}_{\text {max }} / \mathbf{n m}\end{array}$ \\
\hline $\begin{array}{l}\text { CRS polished } \\
\text { CRS immersed in }\end{array}$ & 34 & 50.5 & 379 \\
$\begin{array}{l}0.5 \mathrm{M} \mathrm{H}_{2} \mathrm{SO}_{4} \\
\mathrm{CRS} \mathrm{immersed} \mathrm{in}\end{array}$ & 168 & 208 & 1741 \\
$0.5 \mathrm{M} \mathrm{H}_{2} \mathrm{SO}_{4}+500 \mathrm{ppm}$ of BN & 46.9 & 59.7 & 447 \\
\hline
\end{tabular}

\section{Optical microscopic studies}

The optical microscopic images are taken from Olympus CX31microscopy with Motix camera provided with both trinacular and binocular lenses. The images were taken at 20x magnification with light illuminated at plane polarised and cross Nicols $\left(X_{n}\right)$ condition. It is inferred from the images that the optical microscopic images as in Figure 9a of corroded CRS in $0.5 \mathrm{M} \mathrm{H}_{2} \mathrm{SO}_{4}$ is 
accompanied with cracks and small pits. Whereas, CRS immersed $0.5 \mathrm{M} \mathrm{H}_{2} \mathrm{SO}_{4}+500 \mathrm{ppm}$ of inhibitor BN is protected and is free of cracks and pits as seen in Figure $9 \mathrm{~b}$.

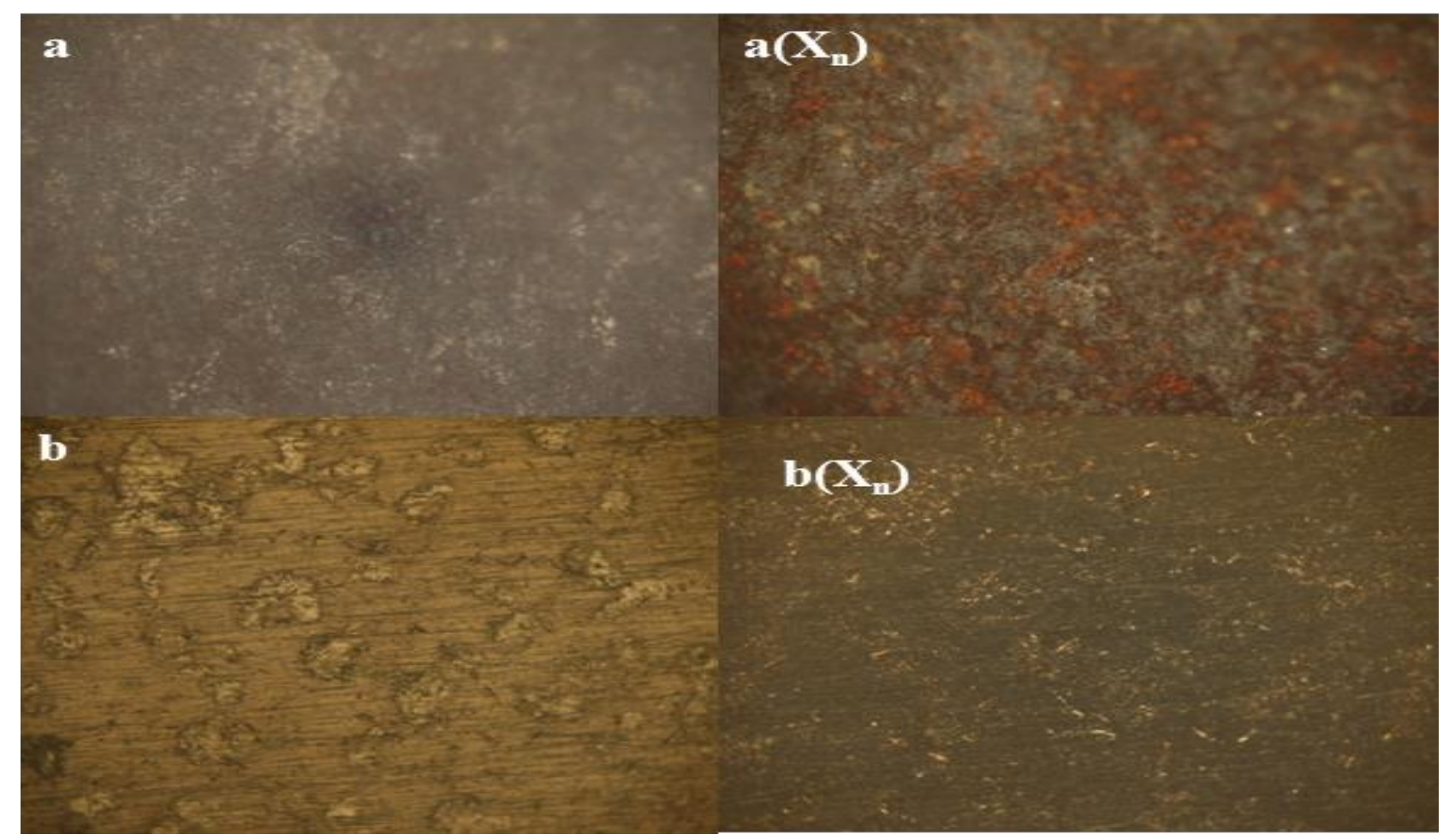

Figure 9. Optical microscopic images of CRS specimens immersed in $0.5 \mathrm{M} \mathrm{H}_{2} \mathrm{SO}_{4}$ [a and a( $\left.\boldsymbol{X}_{n}\right)$ ] and CRS in $0.5 \mathrm{M} \mathrm{H}_{2} \mathrm{SO}_{4}+500 \mathrm{ppm}$ of $B N$ [b and $\left.b\left(X_{n}\right)\right]$

\section{Mechanism of adsorption}

There are many models in the literature to explain the mechanism of adsorption of inhibitors. Generally it is accepted that the adsorption of organic inhibitor molecules is often a displacement reaction involving removal of adsorbed water molecules from the metal surface i.e., $\mathrm{Org}_{(\text {sol) }}+x \mathrm{H}_{2} \mathrm{O}_{\text {(ads) }} \leftrightarrow \mathrm{Org}_{\text {(ads) }}+x \mathrm{H}_{2} \mathrm{O}_{\text {(sol) }}$ [25-28]. The organic inhibitor molecule get adsorbed to the steel surface through its heteroatom like nitrogen, oxygen, sulphur and phosphorus influencing the corrosion properties of steel. The inhibitor molecule adsorbs on to the corresponding active sites of steel and reduces either anodic or cathodic corrosion reactions. There are four primary modes of adsorption associated with inhibitor molecules at surfaces: electrostatic adsorption (physisorption), $\pi$-back bonding, chemisorption, and organometallic complex formation [25]. Thus, the molecule BN can interact with CRS in three possible ways as represented in Figure 10. Firstly, the neutral BN molecule undergoes chemical adsorption to CRS by interaction of lone pair of electrons on nitrogen and oxygen atoms with the empty d-orbitals of iron (a). The second possibility involves the electrostatic interaction of protonated $\mathrm{BN}$ with the already adsorbed $\mathrm{SO}_{4}{ }^{-}$ ions through physisorption (b). The third mode is interaction of $\pi$-electrons of BN molecule with the steel surface through donor-acceptor interaction (c). Thus, adsorption of BN forms a barrier layer on CRS, thereby preventing its contact with the corrosive media and reduces the corrosion rate. 
(a)
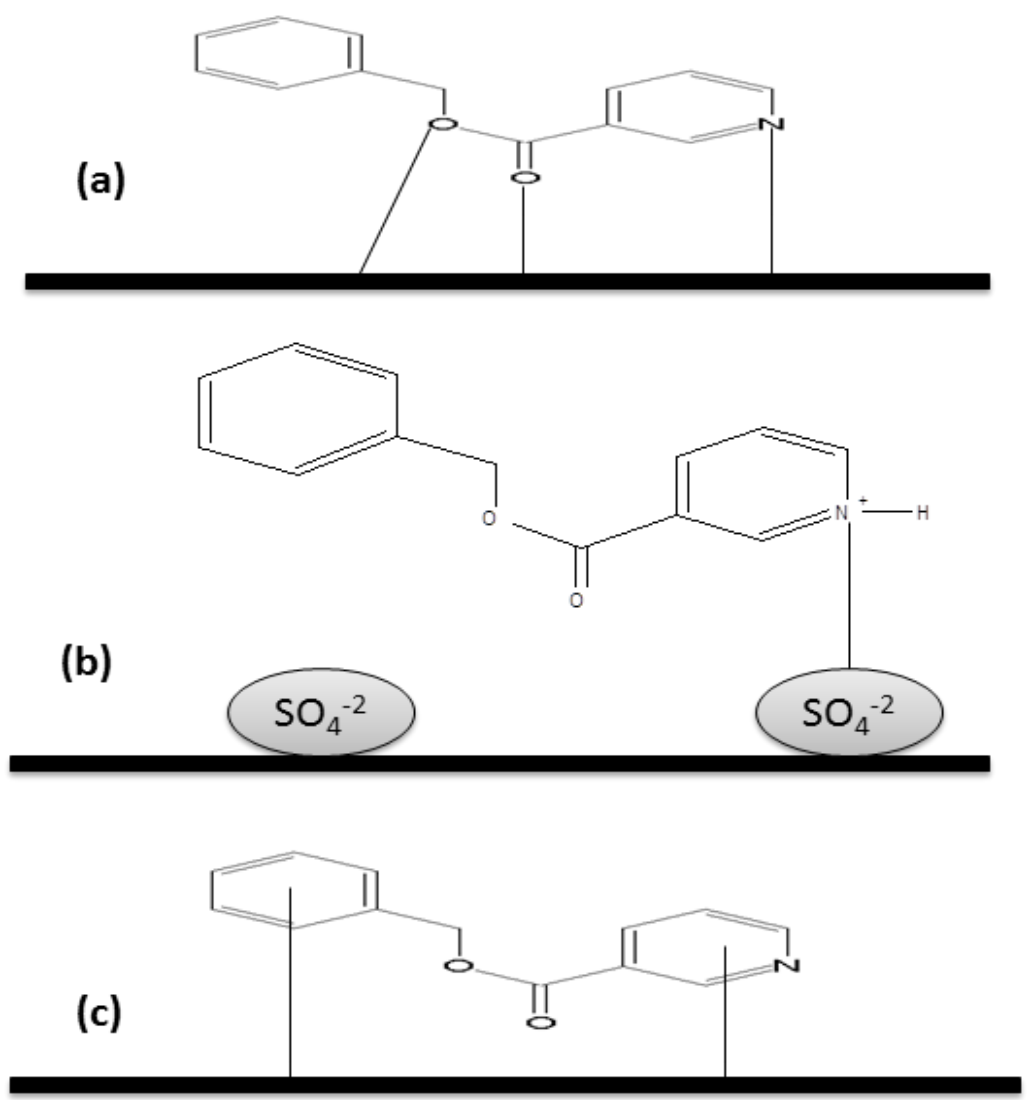

Figure 10. Mechanistic representation of adsorption of $\mathrm{BN}$ on CRS in $0.5 \mathrm{M} \mathrm{H}_{2} \mathrm{SO}_{4}$ solution

\section{Conclusion}

- Benzyl nicotinate (BN) acts as an efficient inhibitor for the corrosion of mild steel in $0.5 \mathrm{M}$ $\mathrm{H}_{2} \mathrm{SO}_{4}$ solution.

- Inhibition efficiency increases with the inhibitor concentration but decrease with temperature. This shows that BN follows physisorption, obeying Langmuir isotherm.

- From the polarisation results it can be concluded that BN acts as mixed inhibitor which impedes both anodic and cathodic corrosion reactions.

- The inhibition efficiency values found from weight loss method are in good agreement with electrochemical findings.

- The morphology of CRS samples were observed by optical microscopy and AFM. Microscopic images and the roughness parameters derived from AFM are supported our experimental findings.

Acknowledgement: The authors are grateful to the University Grant Commission, New Delhi, Government of India for providing financial assistance and Department of Chemistry, Kuvempu University for providing lab facilities.

\section{References}

[1] M. G .Hosseini , M. Ehteshamzadeh , T. Shahrab, Electrochim. Acta 52 (2007) 3680-3685.

[2] Hamdy. H. Hassan, Essam Abdelghani, Mohammed A. Amin, Electrochim. Acta 52 (2007) 6359-6366.

[3] Ling-Guang Qiu, An-Jian Xie, Yu-Hua Shen, Mater. Chem. Phy. 95 (2005) 269-273.

[4] F. Bentiss, M. Lebrini, M. Lagrenee, Corros. Sci. 47 (2005) 2915-2931.

[5] K. F. Khaled, K. Babic-Samardzija, N. Hackerman, J. Appl. Electrochem. 34 (2004) 697-704. 
[6] H. Wang, R.B. Liu , J .Xin , Corros. Sci. 46 (2004) 2455-2466.

[7] S. S. Abd El-Rehim, M. A. M. Ibrahim, K. F. Khaled, J. Appl. Electrochem. 29 (1999) 593-599.

[8] M. A. Quraishi, D. Jamal, J. Appl. Electrochem. 32 (2002) 425-430.

[9] K. Barouni, L. Bazzi , R. Salghi, M. Mihit , B. Hammouti, S .Albourine El Issami , Mater. Lett. 62 (2008) 3325-3327.

[10] T. Jebakumar Immanuel Edison, M. G. Sethuraman ,ISRN Electrochemistry (2013), Article ID 256086, 8 pages.

[11] A. M. Al-Sabagh, N. Gh. Kandil, O. Ramadan, N. M. Amer, R. Mansour, E. A. Khamis, Egyptian J. Pet. 20 (2011) 47-57.

[12] K. Shimizu, A. Lasia, J. F. Boily, Langmuir 28 (2012) 7914-7920.

[13] P. Agarwal, M. E. Orazem, L. H .García-Rubio, J. Electrochem. Soc. 139 (1992) 1917 -1927.

[14] Zhihua Tao, Shengtao Zhang, Weihua Li, Baorong Hou, Ind. Eng. Chem. Res. 50 (2011) 6082-6088.

[15] Sudheer, Mumtaz Ahmad Quraishi, Ind. Eng. Chem. Res. 53 (2014) 2851-2859.

[16] M. Abdallah, I. A. Zaafarany, A .Y .Etre, A. Kamar, Chem. Sci. Rev. Lett. 31 (2015) 348-135.

[17] M. Abdeli, N. P. Ahmadi, R. A. Khosroshahi, J. Solid State Electrochem.15 (2011) 1867-1873.

[18] Ahamad R. Prasad, M. A. Quraishi, J. Solid State Electrochem. 14 (2010) 2095-2105.

[19] Guannan Mu , Xianghong Li, J. Colloid Inter. Sci. 289 (2005) 184-192.

[20] Samy E. Oraby, Ayman M. Alaskari, International Scholarly and Scientific Research \& Innovation 4 (2010) -60.

[21] E. A. Noor, J.Appl. Electrochem. 39 (2009) 1465-1475.

[22] X. H. Li, G. N. Mu, Appl. Surf. Sci. 252 (2005) 1254-1265.

[23] S .Martinez, I .Stern, Appl. Surf. Sci. 199 (2002) 83-89.

[24] Xianghong Li, Shuduan Deng, Hui Fu, Guannan Mu, Corros.Sci. 52 (2010) 1167-1178.

[25] M. P.Desimonea, G. Grundmeier, G. Gordilloc, S. N. Simisona, Electrochim. Acta 56 (2011) 2990-2998

[26] J. O. M. Bockris, D. A. J. Swinkels, J. Electrochem .Soc. 8 (1964) 736 -743.

[27] Xianghong Li, Shuduan Deng, Hui Fua, Taohong Li, Electrochim. Acta. 54 (2009) 4089-4098.

[28] M .Sahin, S. Bilgic, H. Yilmaz, Appl.Surf. Sci. 195 (2002) 1-7.

(C) 2015 by the authors; licensee IAPC, Zagreb, Croatia. This article is an open-access article distributed under the terms and conditions of the Creative Commons Attribution license

(http://creativecommons.org/licenses/by/4.0/) (c) Er ${ }^{\vartheta}$ 